\title{
Lifetime prevalence and correlates of smoking behavior in Iranian adults' population; a cross-sectional study
}

\author{
Ibrahim Abdollahpour ${ }^{1}$ (D), Mohammad Ali Mansournia ${ }^{2}$, Yahya Salimi $^{3,4^{*}}$ (D) and Saharnaz Nedjat ${ }^{5}$
}

\begin{abstract}
Abstact
Background: There are few if any reports concerning the joint use of waterpipe, cigarette and exposure to secondhand smoking in Tehran, Iran. Here, we simultaneously investigated the prevalence and predictors of smoking habits in Iranian adults.

Methods: In this population-based cross-sectional study, we recruited 1057 Iranian adults between August 2013 and February 2015, in Tehran, a multi-ethnic city. Participants were selected using random digit dialing. Three separate logistic regression models were applied to estimate the adjusted odds ratios $(95 \% \mathrm{Cl})$.

Results: Exposure to second-hand smoking was the most prevalent smoking type (37, 95\% Cl: 35-41\%) followed by cigarette (23.9\% (95\% Cl: $21-27 \%)$ ) and water-pipe smoking (20.25\% (95\% Cl: 18-23\%)) in adults in Tehran. Almost 3.3 and $4.5 \%$ of adults reported three and two types of lifetime smoking behaviors, respectively. Age, sex, history of depression along with lifetime alcohol intake was the important predictors of all three types of smoking. Lifetime alcohol consumption was associated with increased prevalence of all three types of smoking ( $p$ for trend $<0.009$ ). Lifetime drug abuse was also associated with increased prevalence of cigarette smoking ( $\mathrm{OR}=2.04,95 \% \mathrm{Cl}: 1.61-2.59$, $p<0.001$ ).

Conclusions: Lifetime prevalence of waterpipe, cigarette and exposure to second-hand smoking is moderately high. Dual smoking behaviors are increasing in Iranian adults. An apparent age-related difference in pattern of waterpipe and cigarette smoking was observed. These findings highlight the need for further educational and preventive programs especially for dual smoking in Iranian young adults. This could provide practical information for evaluating and reforming the tobacco control programs and policies in Iran.
\end{abstract}

Keywords: Population-based cross-sectional study, Cigarette, Second hand, Waterpipe, Smoking, Predictors

\section{Introduction}

Tobacco smoking is one of the main leading global causes of avoidable premature mortality [1] and still remains as one of the main global public health issues [2]. It is responsible for almost 5 million $(\sim 20 \%)$ of the worldwide annual deaths $[3,4]$. It is expected that this number would increase to more than 8 million in 2030 [5], of which around $80 \%$ will occur in countries with low or middle-income level [6]. Its causal role in the

\footnotetext{
* Correspondence: yahya.salimi@kums.ac.ir

${ }^{3}$ Social Development and Health Promotion Research Center, Health institute, Kermanshah University of Medical Sciences, Kermanshah, Iran ${ }^{4}$ Department of Epidemiology and Biostatistics, School of Public Health, Kermanshah University of Medical Sciences, Kermanshah, Iran Full list of author information is available at the end of the article
}

development of adverse health related outcomes including several types of cancer [7-9], chronic diseases $[5,10]$ as well as its high economic cost $[4,11]$ has been proven already.

Waterpipe smoking, also known as hookah, is the oldest form of tobacco smoking [12]. It is not only the most common method of tobacco use among youth in the Middle East, but also it is increasingly becoming an important global tobacco use method [13, 14]. It has been shown in a number of studies that the adverse health outcome of waterpipe smoking is equal to or worse than cigarettes smoking [15]. Evidence supports a positive association between waterpipe smoking and the risk of cancer [16], respiratory and cardiovascular disease $[15,17]$ and multiple

(c) The Author(s). 2019 Open Access This article is distributed under the terms of the Creative Commons Attribution 4.0 International License (http://creativecommons.org/licenses/by/4.0/), which permits unrestricted use, distribution, and 
sclerosis [18]. The common misunderstanding about the less dangerous nature of waterpipe smoking may be responsible for the increasing prevalence of waterpipe smoking [19].

There are substantial differences between and within geographical world regions regarding the prevalence of smoking [4]. The burden of tobacco use in Iran is considerable [20]. Based on the results of a meta-analysis published in 2013, almost $20 \%$ of Iranian male adults smoke [21]. Currently, few surveys simultaneously addressed the prevalence and modifiable correlates of waterpipe smoking, cigarette smoking and exposure to second-hand smoking in Iran. Tehran, the Capital of Iran, with a wide variety of ethnics and mass linguistic groups from all over Iran has provided the opportunity of more generalizable estimates of the smoking pattern and its correlates. Here using a population-based study we tried to investigate smoking pattern and its predictors in 15-50-year-old in Iranian population.

\section{Material and methods}

In this study, we used data of a population-based crosssectional study that was conducted between 2013 and 2015 in Tehran, Iran. [18, 22, 23]. All residents of 22 municipality areas of Tehran aged $15-50$ years constituted the study reference population. Using the standard method of random digit dialing (RDD) the study sample was selected. For generating the random dialing numbers, a 4-digit number was randomly added to the welldefined pre-codes of every 22 municipality areas of
Tehran. The participants were selected proportionally to population size of each 22 areas of Tehran which had been determined in the last national Iranian census report. Using the Kish method [24], we selected one eligible individual in each of the selected household. The Kish method is a detailed process in order to randomly selecting one or more individuals when randomly calling to the households. In sum, it gives priority to the male and older residents and then, based on the participants' gender and age, gives a rank to every resident of household. Using pre-specified specific tables, the Kish method randomly selects one or more individuals among the residents of each household [24]. Detailed recruitment flow-chart of the study participants has been shown in Fig. 1. As demonstrated, 1057 (70.0\%) of 1510 contactable households, within which at least one eligible person existed, have been fully interviewed. Ten trained interviewers conducted the interviews. [18]. At the start of each interview, the participants were informed about the goals of the study and oral consent was obtained. Each interview on average took $15 \mathrm{~min}$.

\section{Data collection protocol}

Ten interviewers which were selected for their strong communication and interview skills, and trained to use the standardized data collection procedures conducted the phone interviews. We monitored the data collection activities for any interviewer bias by randomly recording interviews[18]. At the start of each interview, the participants were informed about the study main objectives.

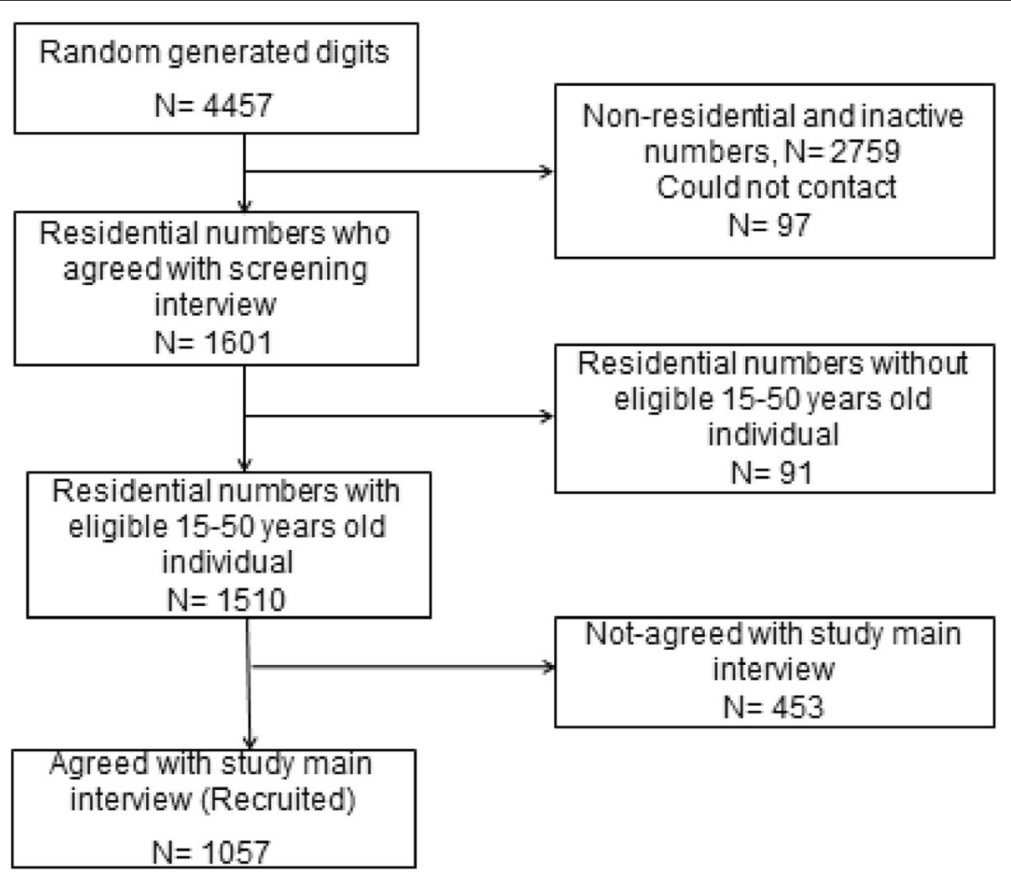

Fig. 1 Detailed recruitment flow diagram of the study participants, Tehran, 2013-2015 
Since the data collection process was conducted using phone interviews, we obtained oral instead written informed consent from all of the participants. In the case of fewer than 16 years old participants, the oral informed consent was obtained from one of their parents.

\section{Measurement}

The participants were requested to provide all required information before the sampling date i.e. the date of recruiting in the study.

\section{Smoking}

Participants who had history of waterpipe smoking for at least once a week for a minimum 6 months were categorized as those with history of waterpipe smoking. We also asked detailed information on duration (years), amount (average frequency per week). We calculated the participants' cumulative waterpipe smoking by multiplying the average frequency per week by 52 weeks and the duration (years) [18, 25]. In addition, information on cigarette smoking (total duration (years), average amount smoked per day, converted to pack-years), exposure to second-hand smoking (ever lived with anyone who regularly smoked, duration (years), timing (before/ after or during 13-19 years))[26] was also obtained. We obtained the data on second-hand smoking for both of smokers and non-smokers.

\section{Lifetime drug use}

We measured any history of drug/substance use asking the following question "Have you ever used any type of substance for at least once monthly during at least a 6month period?" We also collected detailed information on type of drug/substance use i.e. (opioids, cannabis, inhalants, hallucinogens and stimulants), duration (years) as well as amount (average frequency per month). The average frequency of a drug per month was multiplied by 12 and the duration (years), and then was summed for the different drug types in order to calculating the lifetime drug abuse [26].

\section{Lifetime alcohol intake}

Lifetime history of alcohol consumption was defined as any type of alcohol drinking at least 6 times in at least a six-month period. For 4 types of beverages (beer, wine and liquor), detailed information on lifetime alcohol intake (i.e. duration (years), average number of drinks per month and average drink size of each drink $(\mathrm{ml})$ ) were collected [22]. We employed the University of Minnesota's nutrient data system for calculating total lifetime intake of ethanol (g) [27]. This system assigns 12.8, 13.8 and $14.0 \mathrm{~g}$ of alcohol for each $355 \mathrm{ml}$ of beer, $177 \mathrm{ml}$ wine, and $44 \mathrm{ml}$ liquor, respectively. Life-time intake for each source of alcoholic beverage was calculated by multiplying the received gr of specific alcoholic beverage in each drink by the average number of drinks per month, which was multiplied by 12 months and the duration (years) Receivedgrofspecificalcoholicbeverageineachdrink $\times$ averagenumberofdrinkpermonth $\times 12 \times$ duration(year).. Then, total lifetime alcohol consumption (g) was calculated as the sum of three lifetime specific alcoholic beverages. We applied pre-specified categories of alcohol intake for classifying study participations (never, $\leq 500 \mathrm{~g}, 500-5000$, > 5000 g)[26].

\section{History of depression}

Lifetime self-reported history of depression was measured by using the following question: "Have you ever received a diagnosis of depression from a mental health professional?" [28].

\section{Life event number}

Data on the presence of stressful life events (SLE) was obtained asking for example; "Did you experience a serious illness happened for one of your family members?" We collected data on the following SLEs; marriage, death of spouse, death of a loved one including close relatives' (e.g. parent or sibling), divorce, death of one of your dear ones, jail term, retirement, severe illness of family members, family disruption (divorce of the parents), suicide, conquer (national exam for university entrance), dismissal from work, migration, homeless periods, and being in debt as well[26]. The total number of stressful life events was calculated summing all 15 life events resulting in the total stress number.

\section{Physical activity}

Respondents were asked about their physical activity level during adolescence (frequency per week, intensity level (severe or light) and average duration (minutes))[29]. Metabolic equivalent of task (MET) was then calculated using the collected data $[26,30]$.

\section{Demographics variables}

The questionnaire also included demographic questions (age, sex, marital status and years of education,

\section{Statistical analysis}

Logistic regression was used to estimate crude and adjusted odds ratios (ORs) (STATA 12) in 2018. Several variables were examined to detect their association with smoking types including age, sex, marital status, years of education, lifetime alcohol intake, lifetime drug use, stressful life event and history of depression. Test for trend of ordinal categorical variables were undertaken by replacing the binary predictors with a single predictor, taking category rank scores. 


\section{Results}

The detailed recruitment flow-chart of participants is shown in Fig. 1. Of the 1510 contactable households with eligible people, 1057 (70.0\%) agreed to a full interview. The mean age was 31.3 and $51.5 \%$ of them were female. The majority of participants were less than 40 years old (Table 1).

\section{Gender differentials in prevalence of smoking behaviors}

On average males started both cigarette and waterpipe smoking sooner than females (18.95 years old vs. 22.42 years old for cigarette and 19.95 years old vs. 20.85 years old for waterpipe smoking). While a higher proportion of males smoked waterpipe and cigarette for $>5$ and 10 years, the proportion of females exposed to second-hand smoke for $>10$ years is higher. Total current cigarette and waterpipe use was $14.38 \%$ (95\% CI (12-17\%)) and $16.60 \%$ (95\% CI (15-19\%)) in the study population, respectively. More than $35 \%$ of males have reported the life-time experience of cigarette and waterpipe smoking. However, exposure to second-hand smoking (41\%) followed by waterpipe smoking $(13.1 \%)$ is the most common smoking in females (Table 2).

\section{Prevalence of different smoking behaviors}

Smoking is common among 15-50 adult populations. Second-hand smoke exposure (37\% (95\% CI: 35-41\%)), waterpipe smoking (23.90\% (95\% CI: 21-27\%)) and

Table 1 Characteristics of 1057 study population, Tehran, 20132015

\begin{tabular}{ll}
\hline Variables & $N(\%)^{a}$ \\
\hline Female gender & $544(51.50)$ \\
Age at the time of participant (years); mean (SD) & $31.3(9.33)$ \\
Age at the time of participant (Categories) & \\
$\quad<20$ & $349(33.05)$ \\
20 to less than 30 & $362(34.28)$ \\
30 to less than 40 & $209(19.79)$ \\
$40-50$ & $136(12.88)$ \\
Marital status & \\
Single & $462(43.90)$ \\
Married & $591(56.10)$ \\
Highest level of education & \\
Illiterate or primary school (age 7-11 yrs) & $26(2.47)$ \\
Guidance school (age 12-14 yrs) & $60(5.6)$ \\
High school (age 15-18yrs) & $437(41.34)$ \\
Associate's or Bachelor's degree & $441(41.72)$ \\
Master's degree and higher & $93(8.80)$ \\
Years of education (year); mean (SD) & $13.43(3.26)$ \\
\hline a No. (\%), except where otherise indicated. In the case of missing data the
\end{tabular}

${ }^{a}$ No. (\%), except where otherwise indicated. In the case of missing data, the sum of categories is less than 1057 cigarette (20.25, 95\% CI: $18-23 \%)$ smoking are the most common types of smoking respectively (Table 3 ).

\section{Joint use of different types of smoking}

While, more than $42 \%$ of people did not report any smoking experience, $3.3 \%$ of them reported all three types of smoking behaviors. Moreover, $4.5 \%$ of participants reported the lifetime experience of at least two types of smoking (Table 4).

\section{Predictors of three types of smoking}

While life-time waterpipe smoking was significantly associated with an increased prevalence of both cigarette smoking ( $\mathrm{OR}=1.65,95 \% \mathrm{CI}: 1.15-2.36, p=0.007)$ and exposure to second-hand smoking $(\mathrm{OR}=1.47,95 \% \mathrm{CI}$ : 1.12-1.91, $p=0.005)$, lifetime exposure to second-hand smoking was only associated with waterpipe smoking $(\mathrm{OR}=1.47,95 \%$ CI: 1.13-1.92, $p=0.004)$. Similarly, cigarette smoking increased the odds of waterpipe use $(\mathrm{OR}=1.55,95 \% \mathrm{CI}: 1.08-2.21, p=0.018)$ but not exposure to second-hand smoking. While increasing in age significantly increased the life time cigarette smoking, conversely it decreased the probability of waterpipe smoking. Those older than 40 years, had a four-fold decrease in the odds of waterpipe smoking (OR $=0.25,95 \%$ CI: 0.14-0.47, $p<0.001)$. Prevalence of both cigarette and waterpipe in males were significantly higher than females. Females were more likely to expose to secondhand smoking. Lifetime drug abuse only increased the prevalence of cigarette smoking $(\mathrm{OR}=2.04,95 \% \mathrm{CI}$ : 1.61-2.59, $p<0.001)$. However, lifetime alcohol consumption was associated with increased prevalence of all three types of smoking ( $p$ for trend <0.009). Both cigarette and exposure to second-hand smoking were affected by the total number of stressful life events. Education was inversely associated with only exposure to second-hand smoking ( $\mathrm{OR}=0.92$, 95\% CI: 0.89-0.95, $p<0.001)$. The level of physical activity was lower than acceptable of $60.48 \%$ of the study participants. However, the physical activity as well as marriage status was not associated with any types of smoking (data not shown). Finally, the depression history significantly predicted all three smoking with the strongest association with cigarette smoking $(\mathrm{OR}=1.81, \quad 95 \%$ CI $(1.22-2.70))$ followed by waterpipe smoking and second hand-smoking (Table 5).

\section{Discussion}

Using population-based data in Iranian adults, we found exposure to second-hand smoking as the most prevalent smoking behavior (37\%) followed by water-pipe (23.9\%) and cigarette smoking (20.25\%), respectively. Age, sex, history of depression along with lifetime alcohol intake were the important predictors of all three types of 
Table 2 Gender specific prevalence of different types of smoking among adults aged 15-50, Tehran, 2013-2015

\begin{tabular}{|c|c|c|c|c|c|c|}
\hline Variables & Study population N (\%) & Male & Female & Statistical test & OR $(95 \% \mathrm{Cl})$ & $P$ value \\
\hline \multicolumn{7}{|l|}{ Waterpipe Smoking } \\
\hline Never & $803(76.10)$ & $331(64.65)$ & $472(86.92)$ & \multirow[t]{2}{*}{ Simple logistic } & \multirow[t]{2}{*}{$0.27(0.20,0.37)$} & \multirow[t]{2}{*}{$<0.001$} \\
\hline Ever & $252(23.90)$ & $181(35.35)$ & $71(13.08)$ & & & \\
\hline Current & $176(16.70)$ & $127(24.80)$ & $49(9.02)$ & \multirow[t]{2}{*}{ Simple logistic } & $0.27(0.19,0.39)$ & $<0.001$ \\
\hline Past & $76(7.20)$ & $54(10.55)$ & $22(4.06)$ & & $0.28(0.17,0.48)$ & $<0.001$ \\
\hline Age at first Waterpipe Smoking & $20.30(5.65)$ & $19.95(5.45)$ & $20.85(5.93)$ & Simple logistic & $1.05(1.00,1.10)$ & 0.039 \\
\hline \multicolumn{7}{|c|}{ Waterpipe Smoking - duration (years) } \\
\hline$\leq 5$ & $109(10.35)$ & $67(13.09)$ & $42(7.73)$ & \multirow[t]{2}{*}{ Simple logistic } & $0.44(0.29,0.66)$ & $<0.001$ \\
\hline$>5$ & $143(13.55)$ & $114(22.27)$ & $29(5.34)$ & & $0.18(0.12,0.27)$ & $<0.001$ \\
\hline$\leq 250$ & $121(11.5)$ & $67(13.09)$ & $42(7.73)$ & \multirow[t]{2}{*}{ Simple logistic } & 1 & - \\
\hline$>250$ & $127(12.1)$ & $114(22.27)$ & $29(5.34)$ & & $0.28(0.20,0.38)$ & $<0.001$ \\
\hline \multicolumn{7}{|l|}{ Cigarette smoking } \\
\hline Never & $843(79.75)$ & $329(64.13)$ & $514(94.49)$ & \multirow[t]{2}{*}{ Simple logistic } & 1 & - \\
\hline Ever & $214(20.25)$ & $184(35.87)$ & $30(5.51)$ & & $0.1(0.07,0.16)$ & $<0.001$ \\
\hline Current & $152(14.38)$ & $130(25.34)$ & $22(4.04)$ & \multirow[t]{2}{*}{ Simple logistic } & $0.11(0.07,0.17)$ & $<0.001$ \\
\hline Past & $62(5.87)$ & $54(10.53)$ & $8(1.47)$ & & $0.09(0.04,0.20)$ & $<0.001$ \\
\hline Age at first cigarette smoking & $19.67(4.71)$ & $18.95(4.39)$ & $22.42(4.95)$ & Simple logistic & $1.13(1.04,1.23)$ & 0.004 \\
\hline \multicolumn{7}{|l|}{ Cigarette smoking - duration (years) } \\
\hline$\leq 10$ & $122(11.50)$ & $100(19.49)$ & $22(4.04)$ & \multirow[t]{2}{*}{ Simple logistic } & $0.14(0.87,0.22)$ & $<0.001$ \\
\hline$>10$ & $92(8.70)$ & $84(16.37)$ & $8(1.47)$ & & $0.06(0.03,0.13)$ & $<0.001$ \\
\hline \multicolumn{7}{|l|}{ Cigarette smoking (total pack-years) } \\
\hline$\leq 5$ & $165(15.60)$ & $140(27.40)$ & $26(4.78)$ & \multirow[t]{2}{*}{ Simple logistic } & $0.11(0.07,0.18)$ & $<0.001$ \\
\hline$>5$ & $46(4.40)$ & $42(8.22)$ & $4(0.73)$ & & $0.06(0.02,0.17)$ & $<0.001$ \\
\hline \multicolumn{7}{|l|}{ Second-Hand Smoking } \\
\hline Never & $664(63.00)$ & $344(67.32)$ & $320(58.93)$ & \multirow[t]{2}{*}{ Simple logistic } & 1 & - \\
\hline Ever & $390(37.00)$ & $167(32.68)$ & $223(41.07)$ & & $1.43(1.11,1.85)$ & 0.005 \\
\hline \multicolumn{7}{|c|}{ Second-Hand Smoking - duration (years) } \\
\hline$\leq 10$ & $101(9.58)$ & $43(8.41)$ & $58(10.68)$ & \multirow[t]{3}{*}{ Simple logistic } & $1.45(0.95,2.12)$ & 0.085 \\
\hline $10-20$ & $139(13.19)$ & $59(11.55)$ & $80(14.73)$ & & $1.46(1.01,2.11)$ & 0.045 \\
\hline$>20$ & $150(14.23)$ & $65(12.72)$ & $85(15.65)$ & & $1.43(0.98,2.01)$ & 0.062 \\
\hline \multicolumn{7}{|l|}{ Second-Hand Smoking - age period } \\
\hline Before 19 years old & $170(16.13)$ & $83(16.24)$ & $87(16.02)$ & \multirow[t]{3}{*}{ Simple logistic } & $1.13(0.80,1.58)$ & 0.488 \\
\hline After 20 years old & $80(7.59)$ & $24(4.70)$ & $56(10.31)$ & & $2.51(1.52,4.14)$ & $<0.001$ \\
\hline Throughout life & $140(13.28)$ & $60(11.74)$ & $80(14.73)$ & & $1.43(0.99,2.07)$ & 0.055 \\
\hline \multicolumn{7}{|l|}{ Drug abuse } \\
\hline Never & $984(93.27)$ & $445(86.91)$ & $540(90.30)$ & \multirow[t]{2}{*}{ Simple logistic } & 1 & - \\
\hline Ever & $71(6.73)$ & $67(13.09)$ & $4(0.70)$ & & $0.04(0.01,0.12)$ & $<0.001$ \\
\hline \multicolumn{7}{|l|}{ History of depression } \\
\hline Yes & $170(16.14)$ & 55 (10.78) & $115(21.18)$ & Simple logistic & 1 & - \\
\hline No & $883(83.86)$ & $455(89.22)$ & $428(78.82)$ & & $2.22(1.57,3.14)$ & $<0.001$ \\
\hline Physical activity & & & & & & \\
\hline Acceptable MET/week & 415 (39.52) & $301(59.14)$ & $114(21.07)$ & Simple logistic & 1 & - \\
\hline Lower than acceptable & $436(60.48)$ & $208(40.86)$ & 427 (78.93) & & $5.42(4.13,7.11)$ & $<0.001$ \\
\hline
\end{tabular}


Table 3 Age specific prevalence of different types of smoking among adults aged 15-50, Tehran, 2013-2015

\begin{tabular}{|c|c|c|c|}
\hline Variables & $\begin{array}{l}\text { Study population } \\
N(\%)\end{array}$ & $<30$ years & $30-50$ years \\
\hline \multicolumn{4}{|l|}{ Waterpipe Smoking } \\
\hline Never & $803(76.10)$ & $337(69.77)$ & $466(10.5)$ \\
\hline Lifetime & $252(23.90)$ & $147(30.63)$ & 105 (18.39) \\
\hline Current & $176(16.60)$ & $120(24.64)$ & $56(9.81)$ \\
\hline Past & $76(7.20)$ & $27(5.59)$ & 49 (8.58) \\
\hline Age at first waterpipe Smoking & $20.30(5.65)$ & $17.91(3,71)$ & $23.62(6.30)$ \\
\hline \multicolumn{4}{|l|}{ Waterpipe Smoking - duration (years) } \\
\hline$\leq 5$ & $109(10.35)$ & $80(73.040)$ & $29(26.60)$ \\
\hline$>5$ & $143(13.55)$ & $67(46.85)$ & $76(53.15)$ \\
\hline \multicolumn{4}{|c|}{ Waterpipe Smoking - cumulative amount (pipes) } \\
\hline$\leq 250$ & $121(11.5)$ & $68(56.20)$ & $53(43.80)$ \\
\hline$>250$ & $127(12.1)$ & $76(59.84)$ & $51(40.16)$ \\
\hline \multicolumn{4}{|l|}{ Cigarette smoking } \\
\hline Never & $843(79.75)$ & $403(47.86)$ & $440(52.14)$ \\
\hline Lifetime & $214(20.25)$ & $82(38.32)$ & $132(61.68)$ \\
\hline Current & $152(14.38)$ & $63(41.45)$ & $89(58.55)$ \\
\hline Past & $62(5.87)$ & $19(30.63)$ & $43(69.37)$ \\
\hline Age at first cigarette smoking & $19.67(4.71)$ & $17.90(3.37)$ & $20.34(4.74)$ \\
\hline \multicolumn{4}{|l|}{ Cigarette smoking - duration (years) } \\
\hline$\leq 10$ & $122(11.5)$ & $69(56.56)$ & $53(43.33)$ \\
\hline$>10$ & $92(8.70)$ & $13(14.13)$ & $79(85.87)$ \\
\hline \multicolumn{4}{|l|}{ Cigarette smoking (total pack-years) } \\
\hline$\leq 5$ & $165(15.60)$ & $74(44.85)$ & $91(55.15)$ \\
\hline$>5$ & $46(4.40)$ & $7(15.22)$ & $39(84.78)$ \\
\hline \multicolumn{4}{|l|}{ Second-Hand Smoking } \\
\hline Never & $664(63.00)$ & $306(46.50)$ & $358(53.50)$ \\
\hline Lifetime & $390(37.00)$ & $178(45.64)$ & $212(54.36)$ \\
\hline \multicolumn{4}{|c|}{ Second-Hand Smoking - duration (years) } \\
\hline$\leq 10$ & $101(9.58)$ & $57(56.44)$ & $44(43.56)$ \\
\hline $10-20$ & 139 (13.19) & $69(49.64)$ & $70(50.36)$ \\
\hline$>20$ & $150(14.23)$ & $52(34.67)$ & $98(65.33)$ \\
\hline \multicolumn{4}{|l|}{ Second-Hand Smoking - age period } \\
\hline Before 19 years old & $170(16.13)$ & $91(53.53)$ & $79(46.47)$ \\
\hline After 20 years old & $80(7.59)$ & $29(36.25)$ & $51(83.75)$ \\
\hline Throughout life & $140(13.28)$ & $58(41.43)$ & $82(58.57)$ \\
\hline
\end{tabular}

smoking habits. Moreover, cumulative life-event number predicted the cigarette and exposure to second-hand smoking. The lifetime drug abuse was only associated with cigarette smoking. The latest statistics provided by Drope et al. in Tobacco atlas demonstrated that $14.2 \%$ of males and $0.4 \%$ of females smoke cigarettes daily [31]. This is less than our finding $(41.07 \%$ in females vs. $32.68 \%$ in males) in Tehran.
We identified exposure to second-hand smoking as the most prevalent smoking type in adults of Tehran. This finding indicated that current public places smokefree policies may not be effective enough. Moreover, it emphasizes the need for strengthening health-related knowledge and also planning effective health education programs in family environments. In a cross-sectional study enrolled 5900 adults (15-75 years old) in Kerman, 
Table 4 The joint use of different types of smoking, Tehran, 2013-2015

\begin{tabular}{|c|c|}
\hline Variables & $\begin{array}{l}\text { General population } \\
N(\%)\end{array}$ \\
\hline \multicolumn{2}{|l|}{ Cigarette \& Waterpipe smoking ${ }^{a}$} \\
\hline Never cigarette or waterpipe & $683(64.75)$ \\
\hline Just cigarette & $116(11.00)$ \\
\hline Just waterpipe & $159(15.05)$ \\
\hline Both cigarette \& waterpipe & $97(9.20)$ \\
\hline \multicolumn{2}{|l|}{ Cigarette \& second-hand ${ }^{\mathrm{a}}$} \\
\hline Never cigarette or exposure to second-hand & 529 (50.19) \\
\hline Just exposure to second-hand & $312(29.60)$ \\
\hline Just cigarette & $129(12.24)$ \\
\hline Both cigarette \& exposure to second-hand & $84(7.97)$ \\
\hline \multicolumn{2}{|l|}{ Waterpipe \& second hand ${ }^{a}$} \\
\hline Never waterpipe or exposure to second-hand & $513(48.67)$ \\
\hline Just exposure to second-hand & $289(27.42)$ \\
\hline Just waterpipe & $145(13.76)$ \\
\hline Both waterpipe \& exposure to second-hand & $107(10.15)$ \\
\hline \multicolumn{2}{|l|}{ All three types of smoking ${ }^{b}$} \\
\hline Never waterpipe, cigarette or exposure to second-hand & $447(42.41)$ \\
\hline Just waterpipe & $87(8.25)$ \\
\hline Just cigarette & $71(6.74)$ \\
\hline Just exposure to second-hand & $236(22.39)$ \\
\hline Waterpipe \& cigarette & $59(5.60)$ \\
\hline Waterpipe \& exposure to second-hand & $71(6.74)$ \\
\hline Exposure to second-hand \& cigarette & $48(4.55)$ \\
\hline All 3 types of smoking & $35(3.32)$ \\
\hline
\end{tabular}

${ }^{a}$ These are combination of every possible 2 smoking habits

buAll three type of smoking" is every possible combination of all 3 smoking habits

the prevalence of exposure to second-hand smoking was $27.5 \%$ (30.1\% in females vs. $25.0 \%$ in males) [32] which is moderately less than our findings $(41.07 \%$ in females vs. $32.68 \%$ in males). Our estimate is moderately less than one published systematic review by Zeng et al. in 2016 in which the prevalence of exposure to secondhand smoking in Chinese 15-59 years old was 47.1 [33].

In a cross-sectional study in Tehran which recruited 1830 participants, the prevalence of current waterpipe smoking in $\geq 15$ years old was $17.6 \%$ which is similar to our estimates [34]. However, the lifetime prevalence of waterpipe smoking in current study was higher than recent estimates (12\%) for the UK in the 11-16 years old age group [35]. The different recruited age group of the UK study potentially limits the comparability of findings. In California Cigarette Survey study by Smith et.al, $24.5 \%$ of young men (18-24) were ever waterpipe smokers [36]. In a systematic review conducted in 2008 in Middle Eastern countries, the minimum and maximum national reported prevalence of current waterpipe smoking among adults were 5 and 15\%, respectively[13]. While, evidence shows that the prevalence of cigarette smoking is decreasing in developed countries, an observed increasing prevalence of the other forms of tobacco smoking such as waterpipe smoking is highly concerning [36, 37]. A most common public misunderstanding of the less harmful adverse health effects of waterpipe compared to cigarette smoking may be one of the possible reasons for this increasing prevalence [38]. Nonetheless, studies have shown that sweetened flavored tobacco products used in waterpipe, contain several toxicant agents, carcinogenic materials and heavy metals $[39,40]$. Moreover, the carbon monoxide dose as well as the volume of inhaled smoke when smoking waterpipe are very much higher than those in cigarette because of exposure to the charcoal used for heating the waterpipe [15]. There is also evidence demonstrating that wastepipes have adverse short-term and long-term health effects including infectious, respiratory and cardiovascular disease, multiple sclerosis, cancer as well as mental 
Table 5 Three multivariable models demonstrating predictors of three types of smoking habits, Tehran, 2013-2015

\begin{tabular}{|c|c|c|c|c|c|c|}
\hline \multirow[t]{2}{*}{ Predictors } & \multicolumn{2}{|l|}{ Cigarette Smoking } & \multicolumn{2}{|l|}{ Waterpipe Smoking } & \multicolumn{2}{|c|}{ Exposure to Second-Hand Smoking } \\
\hline & Adjusted OR (95\% Cl) & $P$-value & Adjusted OR (95\% Cl) & $P$-value & Adjusted OR (95\% Cl) & $P$-value \\
\hline Lifetime waterpipe smoking & $1.65(1.15-2.36)$ & 0.007 & - & & $1.47(1.12-1.91)$ & 0.005 \\
\hline Lifetime exposure to second hand smoking & $1.19(0.85-1.66)$ & 0.322 & $1.47(1.13-1.92)$ & 0.004 & - & \\
\hline Cigarette Smoking (Lifetime vs. never) & - & & $1.55(1.08-2.21)$ & 0.018 & $1.08(0.77-1.50)$ & 0.663 \\
\hline \multicolumn{7}{|l|}{ Lifetime drug use (cumulative number) } \\
\hline Never & 1 & & 1 & & 1 & - \\
\hline $1-50$ & $6.67(2.52-17.64)$ & $<0.001$ & $1.70(0.76-4.22)$ & 0.229 & $1.15(0.53-2.50)$ & 0.716 \\
\hline $51-500$ & $2.98(1.26-7.07)$ & 0.013 & $1.64(0.81-3.81)$ & 0.219 & $0.76(0.38-1.53)$ & 0.444 \\
\hline$>500$ & $7.84(3.45-17.85)$ & $<0.001$ & $0.75(0.42-1.48)$ & 0.380 & $1.15(0.64-2.09)$ & 0.632 \\
\hline Test for trend & $2.04(1.61-2.59)$ & $<0.001$ & $0.99(0.81-1.20)$ & 0.880 & $1.01(0.85-1.21)$ & 0.881 \\
\hline \multicolumn{7}{|l|}{ Lifetime alcohol intake - cumulative amount (g) } \\
\hline Never & & & 1 & & 1 & - \\
\hline$\leq 500$ & $4.52(2.80-7.29)$ & $<0.001$ & $2.86(1.86-4.40)$ & $<0.001$ & $1.22(0.81-1.84)$ & 0.334 \\
\hline $500-5000$ & $4.54(2.77-7.46)$ & $<0.001$ & $3.93(2.50-6.18)$ & $<0.001$ & $1.33(0.86-2.05)$ & 0.196 \\
\hline$>5000$ & $5.71(3.49-9.34)$ & $<0.001$ & $3.55(2.23-5.67)$ & $<0.001$ & $1.76(1.14-2.72)$ & 0.011 \\
\hline Test for trend & $1.88(1.61-2.18)$ & $<0.001$ & $1.65(1.43-1.91)$ & $<0.001$ & $1.19(1.04-1.37)$ & 0.009 \\
\hline History of depression & $1.81(1.22-2.70)$ & 0.003 & $1.78(1.30-2.44)$ & $<0.001$ & $1.46(1.14-1.89)$ & 0.003 \\
\hline \multicolumn{7}{|l|}{ Categorized life event number } \\
\hline 0 & 1 & & 1 & & 1 & - \\
\hline $1-2$ & $1.77(1.08-2.88)$ & 0.022 & $1.05(0.74-1.52)$ & 0.773 & $1.32(0.99-1.76)$ & 0.059 \\
\hline$>3$ & $1.94(1.15-3.29)$ & 0.013 & $1.28(0.85-1.91)$ & 0.230 & $1.99(1.44-2.75)$ & $<0.001$ \\
\hline Test for trend & $1.32(1.04-1.69)$ & 0.024 & $1.14(0.94-1.39)$ & 0.181 & $1.42(1.21-1.67)$ & $<0.001$ \\
\hline \multicolumn{7}{|l|}{ Age } \\
\hline$>20$ & 1 & & 1 & & 1 & - \\
\hline 20-29.999 & $3.26(1.51-7.03)$ & 0.003 & $1.70(1.05-2.74)$ & 0.029 & $1.31(1.04-2.60)$ & 0.173 \\
\hline 30-39.999 & $3.77(1.75-8.13)$ & 0.001 & $0.86(0.53-1.41)$ & 0.557 & $1.10(0.52-1.36)$ & 0.646 \\
\hline $40-50$ & $5.27(2.37-11.72)$ & $<0.000$ & $0.25(0.14-0.47)$ & $<0.001$ & $1.26(0.75-1.74)$ & 0.293 \\
\hline Male sex & $6.01(3.12-8.77)$ & $<0.001$ & $2.47(1.83-3.34)$ & $<0.001$ & $0.54(0.42-0.70)$ & $<0.001$ \\
\hline Years of education & $0.96(0.91-1.01)$ & 0.122 & $0.99(0.94-1.03)$ & 0.536 & $0.92(0.89-0.95)$ & $<0.001$ \\
\hline
\end{tabular}

health disorders leading to an increased risk of illegal substance use in young people risk $[17,41]$.

In a population-based cross-sectional study in Tehran by Fotouhi et al. which enrolled 3397 residents, the reported prevalence of smoking (11.9\%) was less than our estimate (20.25\%) [42]. This could suggest an increasing trend in cigarette smoking among $15-50$ years old residents of Tehran. The lifetime prevalence of cigarette smoking in males in this study is higher than results of a published meta-analysis in 2014 which reported that nearly $25 \%$ of $15-65$ years old males of northern Iran were ever smokers [43]. Our estimate is also more than a published meta-analysis in 2013 in Iran in which only $20 \%$ of Iranian male adults have reported history of cigarette smoking [21]. The prevalence of three types of smoking habits in males and females were higher than those reported in an Iranian national report by Nemati et.al study. The results of this national report showed that 10.9 and $2.4 \%$ of the Iranian adults were daily cigarette and waterpipe smoker, respectively [44]. Moreover, the estimated joint prevalence of cigarette and waterpipe smoking in the present study was substantially higher than those reported in the Iranian national report by Nemati et.al ( $5.6 \%$ vs. $0.3 \%)$ [44].

The estimated prevalence of cigarette smoking in the current study is comparable with finding of a metaanalyses among Iranian adults published in 2013 [21]. In recent meta-analysis the range of cigarette smoking was reported between 12.3 to $38.5 \%$ in men, and between 0.6 to $9.8 \%$ in women, which is comparable to our estimates [21].

Consistent with a study by Albisser et al. conducted in Switzerland among 204 young adults [45], our findings indicated that waterpipe smoking could predict both 
cigarette and exposure to second-hand smoking habits. Although exposure to second-hand and cigarette smoking were associated with each other, they could not predict engaging in the water pipe smoking.

Alcohol intake was highly correlated with both lifetime waterpipe and cigarette smoking ( $\mathrm{p}$ for trend $<0.05$ ). Consistently, Tamim et al., in a cross-sectional study recruited 1964 students from Lebanon Universities, found that heavy drinkers were more likely to be waterpipe and cigarette smoker [46]. It is well-acknowledged that cigarette smoking can predispose to alcohol and substance use. The possible mechanism of this association is still not clear. As expected, engaging in drug use activities was associated with increased likelihood of cigarette smoking [47]. However, the cross-sectional nature of this design limits the proper interpretation of the temporality between cigarette smoking and drug abuse. Depression was the other factor that predicted waterpipe and cigarette smoking habits but not exposure to second-hand smoking. This was similar to the other studies $[48,49]$, but not all of them [50]. The cumulative number of life time stressful events was associated with both cigarette and exposure to second-hand but not waterpipe smoking ( $\mathrm{p}$ for trend $<0.05$ ). Prior studies have similarly demonstrated that the higher level of stress could directly or indirectly elevate substance use among young people $[51,52]$. Further examination is needed to understand the role of life time stressful events in the context of other forms of tobacco use.

There is a gender difference in the lifetime prevalence of waterpipe (35.3\% in males vs. 13.1 in females) as well as the lifetime prevalence of cigarette smoking (35.9 in males vs. $5.5 \%$ in females) in this study. In general, other than exposure to second-hand smoking, the estimated lifetime prevalence was higher in males than females. This is in line with the results of other studies [44,53]. However, exposure to second-hand smoking was more likely in Iranian females. The later finding shows that women are often affected by the others' smoking behaviors. Contrary to our finding, Riachy et al. in a study, recruited 37,579 participants during 2003 to 2005 in Lebanon, showed that females consumed more waterpipe than males [54]. While the likelihood of cigarette smoking increased with age, reversely, the probability of being waterpipe smoker increased in young adults (20 to 29 years old). This could well demonstrate the age-related differences in pattern of smoking behaviors in Iranian population. Finally, increased years of education could decrease the probability of exposure to the second-hand smoking in the study population.

There are some advantages and limitations that should be considered. This study recruited a population-based data set to describe lifetime prevalence and related factors of waterpipe, cigarette and exposure to second-hand smoking among Iranian 15-50 years old adults. The response rate $(70 \%)$ in this study was found to be satisfactory. Although the usefulness and efficacy of RDD sampling as well as its similarity with address-based sampling were previously demonstrated [55-57], some possibility of selection bias may still have remained. This could affect the validity of study findings. Although we conducted a population-based study in a multiethnic city, the generalizability of the study finding to the whole Iranian population should be done after considering the rural vs. metropolitan differences in smoking behavior. The more stressful nature of metropolitan environments [58], increasing smoking habits in immigrate of the metropolitan areas [59], and finally negative attitude toward smoking habits in the rural areas may differentiate the prevalence of smoking habits in rural area compared to urban area. Considering the illegal nature of alcohol and illicit drugs consumption in Iran society, there was the possibility of the underreporting with respect to these sensitive behaviors. However, we reported one of the largest estimates of the three smoking behaviors as well as alcohol intake and drug abuse compared to the previous studies in Iran. This could alleviate the possibility of a major under reporting. Moreover, the cross-sectional nature of the study design, especially the temporality issue, precluded us from drawing causal conclusions with respect to the identified associations.

\section{Conclusions}

Lifetime prevalence of waterpipe, cigarette and exposure to second-hand smoking is moderately high among Iranian adults. Similarly, compared with previous studies, dual smoking behaviors are increasing in Iranian adults. Age and male sex, history of depression, life time stressful events, drug abuse, alcohol consumption as well as years of education were all found to have moderate correlations with smoking habits. There was an apparent age-related difference in pattern of waterpipe and cigarette smoking behavior in Iranian population. These findings highlight the need for further educational and preventive programs, especially for dual smoking in Iranian young adults, to stress the underlying potential adverse effects of waterpipe smoking. This could provide practical information for evaluating and reforming the tobacco control programs and policies in Iran.

\section{Abbreviations \\ MET: Metabolic equivalent of task; OR: Odds ratios; RDD: Random digit dialing; SLE: Stressful life events}

\section{Acknowledgments}

This project has been a part of Ibrahim Abdollahpour's PhD dissertation in epidemiology (Dissertation Project Number: 93-04-10-240/691). The study was funded by Tehran University of medical science. The authors greatly appreciate the thoughtful comments and recommendations of Professor Luke Clancy (Tobacco Free Research Institute Ireland). 


\section{Authors' contributions}

IA conceived, designed and coordinated the study and prepared the manuscript. YS assisted with statistical analyses and prepared the manuscript. IA, MAM, YS, and ShN contributed to the study design and editing of the manuscript and all authors read and approved the final manuscript.

\section{Funding}

The design of the study and data collection was funded by Tehran University of medical science [grant numbers 8231446$]$. We did not receive any funds for publication of this study.

\section{Availability of data and materials}

The datasets used and/or analyzed during the current study are available from the corresponding author on reasonable request.

\section{Ethics approval and consent to participate}

Since the data collection process was conducted using phone interviews, we obtained oral instead written informed consent from all of the participants. In the case of less than 16 years old participants, the oral informed consent was obtained from one of their parents. The study as well as its verbal consent was approved by the ethics committee of Tehran University of Medical Sciences (approval number: 127334-26145-188-02-93).

\section{Consent for publication}

Not applicable.

\section{Competing interests}

The authors declare that they have no competing interests.

\section{Author details}

${ }^{1}$ Isfahan Neurosciences Research Center, Isfahan University of Medical Sciences, Isfahan, Iran. ${ }^{2}$ Department of Epidemiology and Biostatistics, School of Public Health, Tehran University of Medical Sciences, Tehran, Iran. ${ }^{3}$ Social Development and Health Promotion Research Center, Health institute, Kermanshah University of Medical Sciences, Kermanshah, Iran. ${ }^{4}$ Department of Epidemiology and Biostatistics, School of Public Health, Kermanshah University of Medical Sciences, Kermanshah, Iran. ${ }^{5}$ Department of Epidemiology and Biostatistics, School of Public Health, Tehran University of Medical Sciences, Knowledge Utilization Research Center, Tehran University of Medical Science, Tehran, Iran.

Received: 24 October 2018 Accepted: 23 July 2019

Published online: 06 August 2019

\section{Refrences}

1. WHO. Global health risks: mortality and burden of disease attributable to selected major risks: World Health Organization; 2009.

2. Mzayek F, Khader Y, Eissenberg T, Al Ali R, Ward KD, Maziak W. Patterns of water-pipe and cigarette smoking initiation in schoolchildren: Irbid longitudinal smoking study. Nicotine Tob Res. 2011;14(4):448-54.

3. Rentería E, Jha P, Forman D, Soerjomataram I. The impact of cigarette smoking on life expectancy between 1980 and 2010: a global perspective. Tob Control. 2015:tobaccocontrol-2015-052265.

4. WHO: WHO report on the global tobacco epidemic 2015: raising taxes on tobacco: World Health Organization; 2015.

5. Abubakar I, Tillmann T, Banerjee A. Global, regional, and national age-sex specific all-cause and cause-specific mortality for 240 causes of death, 19902013: a systematic analysis for the Global Burden of Disease Study 2013. Lancet. 2015;385(9963):117-71.

6. WHO. WHO urges more countries to require large, graphic health warnings on tobacco packaging: the WHO report on the global tobacco epidemic, 2011 examines anti-tobacco mass-media campaigns. Cent Eur J Public Health. 2011;19(3):133.

7. Sasco A, Secretan M, Straif K. Tobacco smoking and cancer: a brief review of recent epidemiological evidence. Lung cancer. 2004;45:S3-9.

8. Terry PD, Rohan TE. Cigarette smoking and the risk of breast cancer in women: a review of the literature. Cancer Epidemiol Prev Biomark. 2002;11(10):953-71.

9. Ladeiras-Lopes R, Pereira AK, Nogueira A, Pinheiro-Torres T, Pinto I, Santos-Pereira R, Lunet N. Smoking and gastric cancer: systematic review and meta-analysis of cohort studies. Cancer Causes Control. 2008;19(7):689-701.

10. UDo $H$, Services $H$. The health consequences of smoking - 50 years of progress: a report of the Surgeon General. Atlanta, GA: US Department of Health and Human Services, Centers for Disease Control and Prevention. Office on Smoking and Health: National Center Chronic Dis Prev Health Promot; 2014. p. 17.

11. Goodchild M, Nargis N, d'Espaignet ET. Global economic cost of smoking-attributable diseases. Tobacco Control. 2017:tobaccocontrol2016-053305.

12. Chaouachi K. The medical consequences of narghile (hookah, shisha) use in the world. Revue d'epidemiologie et de sante publique. 2007;55(3):165-70.

13. AkI EA, Gunukula SK, Aleem S, Obeid R, Jaoude PA, Honeine R, Irani J. The prevalence of waterpipe tobacco smoking among the general and specific populations: a systematic review. BMC Public Health. 2011;11(1):244.

14. Maziak W. The waterpipe: a new way of hooking youth on tobacco. Am J Addict. 2014;23(2):103-7.

15. Akl EA, Gaddam S, Gunukula SK, Honeine R, Jaoude PA, Irani J. The effects of waterpipe tobacco smoking on health outcomes: a systematic review. Int J Epidemiol. 2010;39(3):834-57.

16. Montazeri Z, Nyiraneza C, El-Katerji H, Little J. Waterpipe smoking and cancer: systematic review and meta-analysis. Tob Control. 2017;26(1):92-7.

17. El-Zaatari ZM, Chami HA, Zaatari GS. Health effects associated with waterpipe smoking. Tob Control. 2015;24(Suppl 1):i31-43.

18. Abdollahpour I, Nedjat S, Sahraian MA, Mansournia MA, Otahal P, van der Mei I. Waterpipe smoking associated with multiple sclerosis: A population-based incident case-control study. Multiple Sclerosis J. 2017;23(10):1328-35.

19. Aslam HM, Saleem S, German S, Qureshi WA. Harmful effects of shisha: literature review. Int Archives Med. 2014;7(1):16.

20. Meysamie A, Ghaletaki R, Haghazali M, Asgari F, Rashidi A, Khalilzadeh O, Esteghamati A, Abbasi M. Pattern of tobacco use among the Iranian adult population: results of the national Survey of Risk Factors of NonCommunicable Diseases (SuRFNCD-2007). Tob Control. 2010;19(2):125-8.

21. Moosazadeh M, Ziaaddini H, Mirzazadeh A, Ashrafi-Asgarabad A, Haghdoost AA. Meta-analysis of smoking prevalence in Iran. Addiction Health. 2013:5(3-4):140.

22. Abdollahpour I, Nedjat S, Mansournia MA, Sahraian MA, van der Mei I. Lifestyle factors and multiple sclerosis: A population-based incident casecontrol study. Multiple Sclerosis Related Dis. 2018.

23. Abdollahpour I, Nedjat S, Mansournia MA, Schuster T. Estimation of the marginal effect of regular drug use on multiple sclerosis in the Iranian population. PloS one. 2018;13(4):e0196244.

24. Kish L. A procedure for objective respondent selection within the household. J Am Stat Assoc. 1949:44(247):380-7.

25. Dar N, Bhat G, Shah I, lqbal B, Kakhdoomi M, Nisar I, Rafiq R, lqbal S, Bhat A, Nabi S. Hookah smoking, nass chewing, and oesophageal squamous cell carcinoma in Kashmir, India. British J Cancer. 2012;107(9):1618-23.

26. Abdollahpour I, Nedjat S, Mansournia MA, Eckert S, Weinstock-Guttman B. Stress-full life events and multiple sclerosis: A population-based incident case-control study. Multiple Sclerosis Related Dis. 2018.

27. Nelson LM, Matkin C, Longstreth Jr. W, McGuire V: Population-based casecontrol study of amyotrophic lateral sclerosis in western Washington State. II. Diet. Am J Epidemiol 2000, 151(2):164-173.

28. Zimmerman M, Ruggero CJ, Chelminski I, Young D, Posternak MA, Friedman M, Boerescu D, Attiullah N. Developing brief scales for use in clinical practice: the reliability and validity of single-item self-report measures of depression symptom severity, psychosocial impairment due to depression, and quality of life. J Clin Psychiatry. 2006.

29. Craig CL, Marshall AL, Sjorstrom M, Bauman AE, Booth ML, Ainsworth BE, Pratt M, Ekelund U, Yngve A, Sallis JF. International physical activity questionnaire: 12-country reliability and validity. Med Sci Sports Exercise. 2003;35(8):1381-95.

30. Ainsworth BE, Haskell WL, Whitt MC, Irwin ML, Swartz AM, Strath SJ, O Brien WL, Bassett DR, Schmitz KH, Emplaincourt PO. Compendium of physical activities: an update of activity codes and MET intensities. Medicine Sci Sports Exercise. 2000;32(9; SUPP/1):S498-504.

31. Drope J, Schluger N, Cahn Z, Drope J, Hamill S, Islami F, Liber A, Nargis N, M. S. The Tobacco Atlas. American Cancer Society and Vital Strategies: Atlanta; 2018. 
32. Salimzadeh $H$, Najafipour H, Mirzaiepour F, Navadeh S, Shadkam-Farrokhi M, Mirzazadeh A. Prevalence of active and passive smoking among adult population: findings of a population-based survey in Kerman (KERCADRS), Iran. Addiction Health. 2016;8(1):16.

33. Zeng J, Yang S, Wu L, Wang J, Wang Y, Liu M, Zhang D, Jiang B, He Y. Prevalence of passive smoking in the community population aged 15 years and older in China: a systematic review and meta-analysis. BMJ open. 2016;6(4):e009847.

34. Hessami Z, Masjedi MR, Ghahremani R, Kazempour M, Emami H. Evaluation of the prevalence of waterpipe tobacco smoking and its related factors in Tehran, Islamic Republic of Iran/Évaluation de la prévalence de la consommation de tabac par pipe à eau et de ses facteurs associés à Téhéran, République islamique d'Iran. Eastern Mediterranean Health J. 2017;23(2):94.

35. Jawad M, Mclver C, labal Z. Prevalence and correlates of lifetime waterpipe, cigarette, alcohol and drug use among secondary school students in Stoke-on-Trent, UK: a post hoc cross-sectional analysis. J Public Health. 2014;36(4):615-21.

36. Smith JR, Edland SD, Novotny TE, Hofstetter CR, White MM, Lindsay SP, AlDelaimy WK. Increasing hookah use in California. Am J Public Health. 2011 101(10):1876-9.

37. Note WTA. Waterpipe tobacco smoking: health effects, research needs and recommended actions by regulators. Geneva: World Health Organization; 2005.

38. Aljarrah K, Ababneh ZQ, Al-Delaimy WK. Perceptions of hookah smoking harmfulness: predictors and characteristics among current hookah users. Tobacco Induced Diseases. 2009;5(1):16.

39. Fakhreddine HMB, Kanj AN, Kanj NA. The growing epidemic of water pipe smoking: health effects and future needs. Respiratory Med. 2014;108(9): 1241-53.

40. Shihadeh A, Schubert J, Klaiany J, El Sabban M, Luch A, Saliba NA. Toxicant content, physical properties and biological activity of waterpipe tobacco smoke and its tobacco-free alternatives. Tobacco Control. 2015: tobaccocontrol-2014-051907.

41. Martinasek MP, McDermott RJ, Martini L. Waterpipe (hookah) tobacco smoking among youth. Curr Probl Pediatr Adolesc Health Care. 2011;41(2):34-57.

42. Fotouhi A, KHABAZKHOUB M, HASHEMI H, Mohammad K. The prevalence of cigarette smoking in residents of Tehran; 2009.

43. Moosazadeh M, Salami F, Movahednia M, Amiri MM, Afshari M. Prevalence of smoking in northwest Iran: a meta-analysis. Electronic Physician. 2014;6(1):734.

44. Nemati S, Rafei A, Freedman ND, Fotouhi A, Asgary F, Zendehdel K. Cigarette and Water-Pipe Use in Iran: Geographical Distribution and Time Trends among the Adult Population; A Pooled Analysis of National STEPS Surveys, 2006-2009. Archives of Iranian Medicine (AIM). 2017;20(5):295-301.

45. Albisser S, Schmidlin J, Schindler C, Tamm M, Stolz D. Water pipe smoking and its association with cigarette and cannabis use in young adults in Switzerland. Respiration. 2013;86(3):210-5.

46. Tamim H, Terro A, Kassem H, Ghazi A, Khamis TA, Hay MMA, Musharrafieh U. Tobacco use by university students, Lebanon, 2001. Addiction. 2003;98(7):933-9.

47. Mahboubi S, Salimi Y, Shushtari ZJ, Rafiey H, Sajjadi H. Sibling cigarette smoking and peer network influences on substance use potential among adolescent: a population based study. Int J Adolescent Med Health. 2017.

48. Primack BA, Land SR, Fan J, Kim KH, Rosen D. Associations of mental health problems with waterpipe tobacco and cigarette smoking among college students. Substance Use Misuse. 2013;48(3):211-9.

49. Friedman-Wheeler DG, Ahrens AH, Haaga DA, Mclntosh E, Thorndike FP. Depressive symptoms, depression proneness, and outcome expectancies for cigarette smoking. Cognitive Therapy Res. 2007;31(4):547-57.

50. Khademalhosseini Z, Ahmadi J, Khademalhosseini M. Prevalence of smoking, and its relationship with depression, and anxiety in a sample of Iranian high school students. Enliven: Pharmacovigil Drug Saf. 2015;1(1):005.

51. Lawless MH, Harrison KA, Grandits GA, Eberly LE, Allen SS. Perceived stress and smoking-related behaviors and symptomatology in male and female smokers. Addictive Behaviors. 2015;51:80-3.

52. Soto C, Baezconde-Garbanati L, Schwartz SJ, Unger JB. Stressful life events, ethnic identity, historical trauma, and participation in cultural activities: Associations with smoking behaviors among American Indian adolescents in California. Addictive Behaviors. 2015;50:64-9.
53. Sajjadi H, Shushtari ZJ, Mahboubi S, Rafiey H, Salimi Y. Effect of socioeconomic status, family smoking and mental health through social network on the substance use potential in adolescents: a mediation analysis. Public Health. 2018:157:14-9.

54. Riachy MA, Rohayem C, Khoury C, Safi J, Khayat G, Saade-Riachy C, Couche N, Taan G, Geahchan N. Are narguile smokers different from cigarette smokers? Chest. 2007;132(4):527A

55. Massey JT, O'Connor D, Krotki K. Response rates in random digit dialing (RDD) telephone surveys. In: Proceedings of the American Statistical Association, Section on Survey Research Methods: 1997; 1997. p. 707-12.

56. Wacholder S, Silverman DT, McLaughlin JK, Mandel JS. Selection of controls in case-control studies: II. Types of controls. Am J Epidemiol. 1992;135(9):1029-41.

57. Gundersen DA, ZuWallack RS, Dayton J, Echeverría SE, Delnevo CD. Assessing the feasibility and sample quality of a national randomdigit dialing cellular phone survey of young adults. Am J Epidemiol. 2013;179(1):39-47.

58. Meysamie A, Ghaletaki R, Zhand N, Abbasi M. Cigarette smoking in iran. Iranian J Public Health. 2012;41(2):1-14.

59. Hou B, Nazroo J, Banks J, Marshall A. Migration Status and Smoking Behaviors in Later-Life in China_Evidence From the China Health and Retirement Longitudinal Study (CHARLS). Frontiers Public Health. 2018:6:346.

\section{Publisher's Note}

Springer Nature remains neutral with regard to jurisdictional claims in published maps and institutional affiliations.
Ready to submit your research? Choose BMC and benefit from:

- fast, convenient online submission

- thorough peer review by experienced researchers in your field

- rapid publication on acceptance

- support for research data, including large and complex data types

- gold Open Access which fosters wider collaboration and increased citations

- maximum visibility for your research: over $100 \mathrm{M}$ website views per year

At BMC, research is always in progress.

Learn more biomedcentral.com/submissions 